\title{
Effects of light change direction, food deprivation, and sex upon bar pressing in rats
}

\author{
Gene P. Sackett and William E. Wilsoneroft, Jr. \\ PRIMATE LABORATORY, UNIVERSITY OF WISCONSIN; CLAREMONT GRADUATE SCHOOL
}

\begin{abstract}
Abstraet
Light onset effects compared with no change in darkness, and offset compared with no change in the light depended on sex. Males pressed more in light and more to turn light on, females pressed more in darkness and more to turn light off. Deprivation response was higher regardless of light change contingency.
\end{abstract}

\section{Problem}

In studies of light contingent bar pressing, unclear results concerning direction of light change and effect of food deprivation have been obtained (Lockard,1963). The perceptual change hypothesis (Robinson, 1959) assumes that equal changes, regardless of direction, will be equally reinforcing if visual stimulus heterogeneity following a response is equal for each light change direction. The preference hypothesis (Lockard, 1963) assumes that stimulus variables related to the maintenance and test environment and organismic variables determine individual preference functions for light change direction and intensity. The optimal stimulation theory (Leuba, 1955) predicts that light onset alone will reinforce responding because light offset results in stimulation below an optimum level.

With respect to food deprivation, the CampbellSheffield hypothesis (1953) proposes that deprivation produces a lowered threshold of response to external stimulation. This leads to the prediction that without food rewards response frequency should be higher with food deprivation than with food satiation only under conditions of external stimulus change. An opposing view is that deprivation produces a general increase in responsiveness regardless of stimulus change contingencies.

This experiment studied the initial reaction of light reared animals, who had experienced neither food deprivation nor darkness, to light onset, offset, or no change under food deprived and satiated conditions. Expectations were that lever pressing frequency would be greater under deprivation only if light change followed the response, and that both light onset and offset would produce response levels greater than those of no light change controls.

\section{Method}

Subjects were male and female hooded rats $(N=80)$, approximately 125 days old, maintained from birth on ad lib food and water in a 24-hr. lighted environment. The apparatus, a Davis Instruments Model DB-101 Skinner box, was placed in a semi-sound proof room inside a cardboard box. A bulb mounted on top of the apparatus produced illumination of $6.5-\mathrm{ft}$ candles at the lever.
Stimulus change was varied in 2 main conditions: (a) light change, in which a lever press produced change from light to dark for the light offset group, or change from dark to light for the light onset group; and (b) no light change, with 1 group run in the dark and 1 in the light. Two adaptation light level conditions included (a) the Ss run in the dark (dark, no change and dark-tolight change groups), and (b) the Ss run in the light (light, no change and light-to-dark change groups). Each of the 2 light change and 2 no change groups contained 5 food deprived males and 5 satiated males, and 5 deprived and 5 satiated females. The 40 satiated Ss had ad lib food and water, the other $40 \mathrm{Ss}$ were $23-\mathrm{hr}$. food deprived with $1-\mathrm{hr}$. daily feeding and ad lib water for 7 days. On day 8 , all $\mathrm{Ss}$ received 10-min. adaptation in the apparatus with the lever absent and light on or off depending on the adaptation light level to be used on the test trial. The 5-min. test trial commenced $12 \mathrm{hr}$. after adaptation. Timing of the trial began when $\mathrm{S}$ made its first lever press. Light change lasted for the duration of each press.

\section{Results}

Analysis of variance revealed that deprived Ss $(\overline{\mathrm{X}}=17.5)$ pressed more than satiated $(\overline{\mathrm{X}}=11.9)$ $(\mathrm{P}<.01)$. Figure 1 shows that no interaction occurred

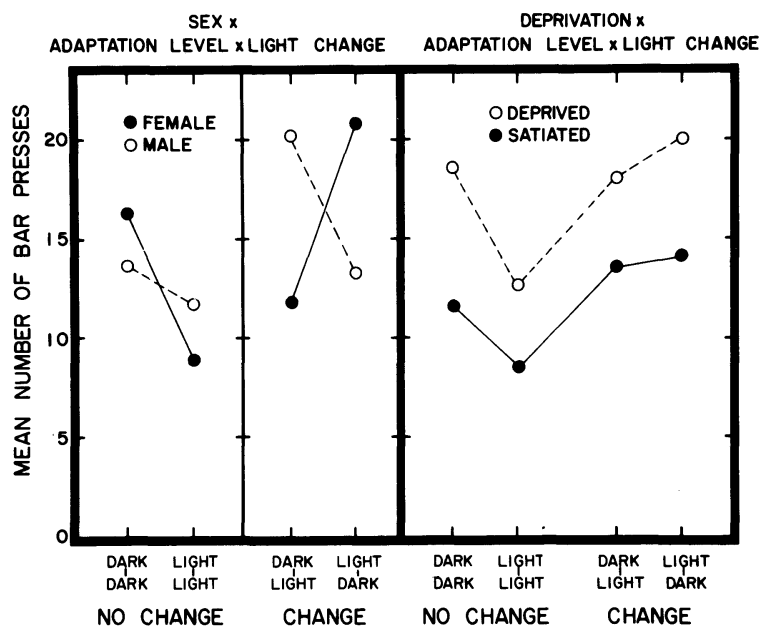

Fig. 1. Interaction of sex, light change, and adaptation light level, and interaction of food deprivation, light change, and adaptation light level. Experimental conditions are specified with the adaptation light level preceeding the dash and the light contingency following bar pressing after the dash. 
between food deprivation, adaptation light level, and light change $(F<1.00)$, deprivation uniformly and equally raising response level in all groups.

Although the mean response frequency of 16.4 under light change was higher than the mean of 12.9 under no light change $(\mathrm{P}<.05)$, the light change $\mathrm{X}$ adaptation level $X$ sex interaction, shown in Fig. 1, was significant $(\mathrm{P}<.01)$. Specific comparisons revealed that (a) for males the light onset mean of 20.2 was greater than the dark, no change, control mean of $13.9(\mathrm{P}<.05)$, while for females the light onset mean of 11.7 was somewhat, but not significantly, less than the dark, no change, mean of 16.3; and (b) for males the light offset mean of 13.3 differed little from the light, no change, mean of 11.8 , while for females the light offset mean of 20.8 was higher than the light, no change, mean of $9.1(\mathrm{P}<.01)$. A final result revealed that in the no light change condition, the mean of $\mathbf{1 5 . 1}$ for Ss run in the dark was higher than the mean of 10.4 for Ss run in the light $(P<.02)$. This effect did not depend on sex.

\section{Discussion}

The lack of interaction between stimulus change and food deprivation appears to invalidate the CampbellSheffield notion of heightened response threshold to stimulus change under food deprivation for this barpressing situation. Instead, deprivation generally raises response level regardless of stimulus change contingencies.

The dependence of light change effects upon sex indicates a sex-determined differential preference for light in hooded rats. Thus, (a) males are more responsive than females in the light, and males press more to turn a light on, while (b) females are more responsive than males in the dark, and females press more to turn a light off. Apparently there is a preference for darkness by females and for light by males. The reason for this effect is not clear. It seems unlikely that cyclic hormonal factors can account for the data, the probability being very low that 40 female rats would be in about the same estrous stage. However, if repeatable, this result is critical for testing any theory of light change behavior, as different functional relationships would be needed to predict the behavior of males and females. An effect similar to this one has been found in a developmental study of light contingent bar pressing (Sackett, 1963), with females responding at a higher rate in the dark and males at a higher rate in the light.

The behavior of the dark, no light change group, presents an apparently anomalous effect. Although this group received no light change, response level was higher than in the light, no change group, and almost at the level of the light change group. A possible explanation concerns the fact that in the light, no change condition, all of the tactile, kinesthetic, and auditory stimulation from the bar mechanism is present, but also available are visual stimulus changes from scanning the apparatus and the S's own movements. These visual changes may compete with changes contingent on bar pressing, thereby depressing response frequency. Such competing responses are absent in the dark, no change, condition. In the face of the stimulus impoverishment of the dark environment, the minimal tactile, auditory, and kinesthetic changes produced by bar pressing may become particularly salient, resulting in relatively high response frequencies.

\section{References}

CAMPBELL, B. A., \& SHEFFIELD, F. D. Relation of random activity to food deprivation. J.comp. physiol. Psychol., 1953, 46, 320-32.

LEUBA, C. Toward some integration of learning theories: The concept of optimal stimulation. Psychol. Rep., 1955, 1, 27-33.

LOCKARD, R. B. Some effects of light upon the behavior of rodents. Psychol. Bull., 1963, 60, 509-529.

ROBINSON, J. S. Light onset and termination as reinforcers for rats living under normal light conditions. Psychol. Rep., 1959, 5, 793-796.

SACKETT, G. P. The maturation and development of learning, motivated by changes in light stimulation. Unpublished Doctoral Dissertation, Claremont Graduate School, 1963.

\section{Note}

1. This study reports a portion of the first author's dissertation for partial fulfillment of the requirements for Doctor of Philosophy degree, Claremont Graduate School, Claremont, California; and was supported by USPHS Pre-Doctoral Fellowship MF-10,710 to the first author. 